\section{Back to the freeze?}

A COUPLE of years ago (January 10, 1975) we reported on an extremely gloomy set of figures which showed how openings for senior university posts in the United Kingdom had all but disappeared in 1974 as a result of a general freeze in hiring. We have now brought the figures up to date by analysing advertisements for the years 1975 and 1976. Things are, at least temporarily, much better.

In the past two years the level of hiring seems to have been back fairly close to the levels of the late 1960s and early 1970s. Of course this indicates that the backlog has not been, and is never likely to be cleared. Some posts have disappeared for ever. But it may help to shake loose, in the course of time, the rigidity with which the universities were beginning to be afflicted. That is, unless the next rather ominous cloud on the horizon can be dispersed.

That cloud is the recent warning by the University Grants Committee that next year's (1977-8) grant to universities for salaries, maintenance and capital expenditure could be as much as $4 \%$ down in real terms. This figure first appeared in mid-1976 when the raising of student fees was seen by the Department of Education and Science not only as a way of bringing in more revenue to universities but also as a restraint on growth in student numbers and therefore in university financial needs. Since then there has been much re-adjustment, including the recent public expenditure cuts, but the result of it all is that we are back to the figure of $4 \%$ as the basis for discussion and warning.

Three quarters of all UGC disbursements go on salaries and so the next round of the national pay policy, not yet openly discussed, could make the figure look disastrousor even quite tolerable; such is the uncertainty in which universities, once used to quinquennial planning, now live. But whatever happens there is a limit to the amount that can be saved by not painting, not cleaning and not heating. Very soon we could be back to solving the universities' financial problem by again venturing on the capricious course of not hiring.

\title{
Amaze, test, shock your friends
}

THE festive season permits us to see ourselves as others see us and no better than through the scientific books, toys and kits showered on our children-and ourselves.

Here we have a book in which it says that if you drop a slice of buttered bread from a height it will land more often with its buttered side down. This is because the layer of butter makes one side heavier so "there is a tendency for the butter-side to fall faster". Yet further on we are told that in the absence of air "heavy things and light ones get up speed with the same degree of acceleration". And to complete the confusion we hear about a lorry with a load of canaries. When the birds all fly up in their cages "the weight on the tyres is reduced".

Or here is an excellent planisphere to show the position of the stars. The stars, it says on the back "appear to move in the same way as the sun" except that the "apparent movement of constellations near Polaris is more limited". And your absolute beginner, venturing out just after Christmas in the early evening might wonder why a couple of the most prominent 'stars' in the sky don't rate a mention.

They do get mentioned elsewhere in an encyclopedia for boys and girls. "The Universe is made up of the Earth we live on, the Sun and its other planets, thousands of other small bodies-and space itself . . . a planet is a big ball of rock and gas".

Nothing about astronomy in the Super Quiz Book for Girls; the question on stars runs "where were Paul
Newman and Omar Sharif born?" In the same book there is a picture of a lady in a white coat which bears the label 'UKAEA'. A machine is applying lipstick by remote control-" Of course, the machine was developed for handling radioactive materials, but something like it may well one day be in every home". The same quiz book also offers intelligence tests-"use these tests to see how much quicker and brighter you are becoming, how you compare with your friends".

Home experiments seem to have become simpler and certainly safer with the years. No longer do you "hold the two handles of the induction coil and gradually insert the steel rod until you can no longer bear the tingling sensation. Compare your performance with that of your friends". But even a book of delightfully simple experiments has an oddity or two. Place a bottle between your mouth and a lighted candle. Why does the flame go out when you blow? "The air moving past the bottle creates a partial vacuum behind the bottle, and the air rushing in to fill this vacuum puts out the flame".

After junior science, the children can at least retreat into the unambiguous world of their first knitting kit"Place a needle under your left arm. Hold the end of the yarn tightly in your left hand. Take the yarn coming from the ball into your right hand between your thumb and middle finger. Turn your index under the yarn between your hands towards you and point your index forward. There is a loop on your index". 